\title{
Comparison of seven sets of criteria used for the diagnosis of vascular dementia
}

Citation for published version (APA):

Verhey, F. R. J., Lodder, J., Rozendaal, N., \& Jolles, J. (1996). Comparison of seven sets of criteria used for the diagnosis of vascular dementia. Neuroepidemiology, 15(3), 166-172.

https://doi.org/10.1159/000109904

Document status and date:

Published: 01/01/1996

DOI:

10.1159/000109904

Document Version:

Publisher's PDF, also known as Version of record

\section{Please check the document version of this publication:}

- A submitted manuscript is the version of the article upon submission and before peer-review. There can be important differences between the submitted version and the official published version of record.

People interested in the research are advised to contact the author for the final version of the publication, or visit the DOI to the publisher's website.

- The final author version and the galley proof are versions of the publication after peer review.

- The final published version features the final layout of the paper including the volume, issue and page numbers.

Link to publication

\footnotetext{
General rights rights.

- You may freely distribute the URL identifying the publication in the public portal. please follow below link for the End User Agreement:

www.umlib.nl/taverne-license

Take down policy

If you believe that this document breaches copyright please contact us at:

repository@maastrichtuniversity.nl

providing details and we will investigate your claim.
}

Copyright and moral rights for the publications made accessible in the public portal are retained by the authors and/or other copyright owners and it is a condition of accessing publications that users recognise and abide by the legal requirements associated with these

- Users may download and print one copy of any publication from the public portal for the purpose of private study or research.

- You may not further distribute the material or use it for any profit-making activity or commercial gain

If the publication is distributed under the terms of Article $25 \mathrm{fa}$ of the Dutch Copyright Act, indicated by the "Taverne" license above, 


\section{Neuroepidemiology}

Neuroepidemiology $1996 ; 15: 166-172$
Hans R, Jehey a

Ian Lodderbic:

Noo Rozendaala,

Jellemer Jolles a,c

Departments of

"Psychiatry and Neuropsychology, Section of Neuropsychology,

Neuropsychiatry and

Psychobiology, and

1) Neurology.

- State University of Limburg, and University Hospital of Maastrichi, Maastricht, The Netherlands

\section{Key Words}

Vascular dementia

Diagnostic criteria

Alzheimer's disease

Ischenic scales

\section{Comparison of Seven Sets of Criteria Used for the Diagnosis of Vascular Dementia}

\begin{abstract}
At least seven different sets of criteria are commonly used for the diagnosis of wascular dementia ( $\mathrm{VaD}$ ). These are the ischemic scales (IS) of Hachinski, Rosen and Loeb, the criteria from the DSM-III-R, those outlined by Erkinjuntti et al., the State of California Alzheimer's Disease Diagnostic and Treatment Centers (ADDTC) and the international workgroup of the American National Institute of Neurological Disorders and Stroke (NINDS) and the European "Association Internationale pour la Recherche et l'Enseignement en Neurosciences". To investigate the differences and similarities of these criteria, we applied them to a sample of 124 demented patients from the Maastricht Memory Clinic. Only 8 patients were diagnosed as having $\mathrm{VaD}$ by all criteria. Depending on which criteria were used, the frequencies of $\mathrm{VaD}$ and Alzheimer's disease (AD) ranged from 6 to $32 \%$, and from 48 to $56 \%$, respectively. The IS of Hachinski and Rosen resulted in the highest frequencies of $\mathrm{VaD}$, whereas the criteria of Erkinjuntti and those from the ADDTC and the NINDS workgroup yielded the lowest. The number of patients with $\mathrm{VaD}$ was reduced substantially when neuroradiological data and the temporal relationship between stroke and dementia were taken into consideration. We conclude that the seven sets of criteria cannot be regarded as interchangeable. Differences in the criteria for $\mathrm{VaD}$ and $\mathrm{AD}$ may be an overlooked source of interstudy variance.
\end{abstract}

\section{Introduction}

The differentiation between Alhzeimer's disease (AD) and vascular dementia (VaD) is important not only from a clinical viewpoint
$[1,2]$, but also for epidemiological research [3]. At least seven instruments have been purposed for the diagnosis of $\mathrm{VaD}$ in the last 20 years, and all are currently used for clinical and research goals. The aim of the present

\section{KARGER}

E-Mail katgentratager

Fiax +416130612.34
(1) 1996 S Karger AC. Basel $0251-5350 / 960153-0166 \$ 10.60 / 0$
F.RJ. Verhey, PhD MD

Department of Psychiatry

University Hospilal of Masustridht

POB BOX 5800

NL -6202 AZ Malastricht (The Netherlandsy 
study was to examine whether, and to what extent, the different criteria can be regarded as interchangeable. This has implications for the comparison of studies of $\mathrm{VaD}$ or $\mathrm{AD}$ carried out with the various criteria. Therefore, we applied the seven sets to a sample of demented patients visiting a university hospi$\mathrm{tal}_{\text {, }}$ in order to compare the prevalence rates of $\mathrm{VaD}$ and $\mathrm{AD}$ as detected by each criterion and to obtain insight into the similarities and differences between the various criteria.

\section{Patients and Methods}

\section{Patients}

The data of patients with dementia $[4,5]$ who were consecutively referred to the Maastricht Memory Clinic were used for this study. The diagnostic procedure has been described elsewhere [6] and includes: a semistructured history provided by the patient and the caregiver, a standardized psychiatric interview, and internal, neurological examination and neuropsychological investigation, laboratory tests and a CT scan of the brain (in most cases using the Philips Tomoscan 310). A neurologist experienced in cerebrovascular pathology (J.L.) examined all CT scans for the presence of (lacunar or cortical) infarctions and leukoaraiosis, according to standardized criteria [7]. Only CT scans made during the assessment of dementia, and not those made earlier in the acute stage of a stroke, were used for this siudy.

\section{Methods}

Seven different sets of criteria for the diagnosis of $\mathrm{VaD}$ were studied. The criteria are shown in table 1.

The ischemic scale (IS) of Hachinski et al. (H-IS) $[8]$ consists of 13 items related to the course, risk factors, behavioral features and neurological signs and symptoms. Rosen et al. [9] validated the H-IS by using the pathological data of 14 patients; in their version of the IS (r-IS), they omitted 5 of the original F-IS items that did not contribute to the clinical differentiation between $\mathrm{AD}$ and $\mathrm{VaD}$. Loeb [10] and Gandolfo [11] validated the H-IS by using CT scan data from 101 patients with denentia and proposed their own version of the IS (L-IS). On the basis of these findings, the L-IS included only 4 of the original H-IS items and was expanded to include single or multiple low-density areas on $C T$ scans $[10,11]$. The criteria for $\mathrm{VaD}$ from the DSM-III-R [4], comprise, besides the presence of dementia: (1) the presence of a stepwise deteriorating course with a patcly distribution of deficits; (2) focal meurological signs and symptoms, and (3) evidence from history, physical examination or laboratory tests of significant cerebrovascular disease, judged to be etiologically related to the disturbance. In the DSM-IV criteria [5], which were not yet avalable at the time of this sidy, the first of these criteria is omitted. Erkinjuntt i et al. [12. 13] defined VaD, mult-irfarct lype, as idementia evolving in connection with acute neurological symptoms or signs and/or findings on CT indicating multiple cortical and/or deep vascular lesions of the brain'. Recently, similar criteria for the diagnosis of $\mathrm{Va}$ a have been suggested by the State of California Alzheimer's Disease Diagnostic and Treatment Centers (ADDTC) [14] and by an international workgroup of the American National institute of Neurological Disorders and Stroke (NINDS) and the European Association Intemationale pour la Recherche et I'Enseignement en Neurosciences" (AIREN) [15]. In these recent proposals, less emphasis is put on course characteristics and behavioral features; neuroimaging evidence of an infaret (by $\mathrm{Cr}$ or $\mathrm{MRO}$ ) is necessary, and at least wo ischemic strokes are required, or, in the case of one stroke, the evidence of a temporal relationship to the onset of dementia.

Soon after the workup, all relevant clinical data of each patient were entered in the database of the Maastricht Memory Clinic. These included, among others, all items from the H-IS, the number, type and localiza* tion of the strokes, relevant CT scan data, existence of a temporal relationship with the onset of dementia and clinical features of Binswanger's disease as defined in the ADDTC report (urinary incontinence, vascuiar risk factors and extensive white-matter changes on $\mathrm{CT}$ scans) [14]. Thus, although many of the paticnts had been assessed before, the more recent criteria were published, the difterent sets of criteria could be applied in retrospect. The only unavailable data pertained 10 the DSM-III-R criterion for VaD, of a 'patchy distribution of deficits". This aspect was ignored because it was felt that it could not be easily used in practice. Cut-off scores for $\mathrm{VaD}$ and $\mathrm{AD}$ were used as described in the original publications. Four diagnostic categories were used: (1) VaD, including "multi-infarct demential scores above the cul-off yalues of the ISs [8-101, "multi-infarct dementia' by the DSM criteria, [4], VaD multi-infarct type [12], and 'probable VaD' [14, 15]; (2) mixed dementia, an intermediate category for patients with IS scores between the cut-off walues for $\mathrm{VaD}$ and $\mathrm{AD}$, probable and hemodynamic-type $\mathrm{VaD}$ [12] and possible $\mathrm{VaD}[14,15]$; (3) AD, including the patients who formed the 'counterpart' of $\mathrm{VaD}$, i.e. ful- 
Table 1. The items of seven sets of criteria for the diagnosis of $\mathrm{VaD}$

\begin{tabular}{lllllllll}
\hline & H-IS & R-IS & LIS & DSM & ERK & ADDTC NINDS \\
& 1975 & 1980 & 1982 & $1980 / 87$ & 1986 & 1992 & 1993 \\
\hline Dementia & + & + & + & + & + & + & $+^{1}$ \\
Abrupt onset & 2 & 2 & 2 & - & + & - & $\pm^{2}$ \\
Stepwise deterioration & 1 & 1 & - & + & - & - & - \\
Fluctuation & 2 & - & - & - & - & - & - \\
Nocturnal confusion & 1 & - & - & - & - & - & - \\
Preserved personality & 1 & - & - & + & - & - & - \\
Depression & 1 & - & - & - & - & - & - \\
Somatic complaints & 1 & 1 & - & - & - & - & - \\
Emotional lability & 1 & 1 & - & - & - & - & - \\
Hypertension & 1 & 1 & - & - & - & - & - \\
History of strokes & 2 & 2 & 1 & + & - & + & + \\
Signs of atherosclerosis & 1 & - & - & - & - & - & - \\
Focal neurological symptoms & 2 & 2 & 2 & + & + & + & + \\
Focal neurological signs & 2 & 2 & 2 & + & + & + & + \\
Low-density area on CT scan & - & - & $2 / 3^{3}$ & \pm & + & + & + \\
Multiple strokes & - & - & - & \pm & + & +4 & \pm 2 \\
Temporal relation & - & - & - & - & +5 & +6 & - \\
\hline
\end{tabular}

$\mathrm{ERK}=$ Criteria of Erkinjuntti et al $._{. ;}+=$obligatory; $\pm=$ambiguous.

1 Defin ition of dementia slightly different; neuropsychological testing obligatory.

2 Either multiple strokes or 1 single stroke with abrupt onset of dementia.

3 Either isolated ( 2 points) or multiple (3 points) hypodense areas on CT scan.

4. At least 1 infarct outside the cerebellum.

5 In absence of a temporal relation: probable $\mathrm{VaD}$.

6 In case of a single stroke.

fllting regular research criteria for $\mathrm{AD}$ [16], using the corresponding criteria to exclude $\mathrm{VaD}$, and (4) unclassifiable, a category formed by the patients who could not be classified in any of the above categories.

The agreenent between the different sets of criteria was assessed by calculating the $k$ statistics. $k$ is the rate of observed agrement between a single pair of sets adjusted for the proportion of the agreement that can be expected to occur by chance.

\section{Results}

One hundred and twenty-four patients were included in this study. The mean age of the patients was $70.1 \pm 8.8$ years. In 25 patients, the examination yielded a cause oth- er than a cerebrovascular or primary degenerative cause (e.g. Parkinson's disease, frontal lobe dementia or alcohol abuse), leaving 109 patients for further differentiation between $\mathrm{VaD}$ and $\mathrm{AD}$. These patients were mildly or moderately demented, as reflected by a mean score of $17.9 \pm 5.8$ on the Mini Mental State Examination [17].

Thirty-nine had VaD according to at least one set of criteria, whereas only 8 patients were diagnosed as having $\mathrm{VaD}$ by all sets of criteria. Seventy-five patients had AD diagnosed by at least one set of criteria, whereas 51 patients were diagnosed as such by all sets. Table 2 shows the numbers of patients diagnosed according to each criterion. 
Table 2. Frequencies of $\mathrm{VaD}$ and $\mathrm{AD}$ among 124 patients with dementia, using different sets of criteria

\begin{tabular}{|c|c|c|c|}
\hline Category & Criterion & $\mathrm{n}$ & $\%$ \\
\hline \multicolumn{4}{|c|}{$H-I S(1975)[18]$} \\
\hline $\mathrm{VaD}$ & score $\geq 7$ & 32 & 26 \\
\hline Mixed & score $>4$ and $<7$ & 10 & 8 \\
\hline $\mathrm{AD}$ & NINCDS-ADRDA and $H$-IS score $\leq 4$ & 65 & 52 \\
\hline \multicolumn{2}{|c|}{ Unclassifiable } & 2 & \\
\hline \multicolumn{4}{|c|}{$R-I S(1980)$} \\
\hline $\mathrm{VaD}$ & score $\geq 4$ & 36 & 29 \\
\hline Mixed & score of 3 & 6 & 5 \\
\hline $\mathrm{AD}$ & NINCDS-ADRDA and L-IS score $\leq 2$ & 64 & 52 \\
\hline \multicolumn{2}{|c|}{ Unclassifiable } & 3 & 2 \\
\hline \multicolumn{4}{|c|}{$L-I S(1982)$} \\
\hline $\mathrm{VaD}$ & scome $\geq 5$ & 23 & 19 \\
\hline Mixed & score of 3 or 4 & 12 & 10 \\
\hline $\mathrm{AD}$ & NINCDS-ADRDA and L-IS score $\leq 2$ & 70 & 56 \\
\hline \multicolumn{2}{|c|}{ Unclassifiable } & 4 & 3 \\
\hline
\end{tabular}

DSM-III-R (1980/1987)

$\begin{array}{llll}V a D & M I D & 15 & 12\end{array}$

$\begin{array}{llll}\text { Mixed not covered by DSM criteria } & 0 & 0\end{array}$

$\begin{array}{llll}\text { AD } & \text { primary degenerative dementia } & 59 & 48\end{array}$

$\begin{array}{lll}\text { Unclassifiable } & 35 & 28\end{array}$

Erkinjtanti's crilevia (1986)

\begin{tabular}{llrr} 
VaD & MID & 14 & 11 \\
Mixed & PVD and hemodynamic-type dementia & 26 & 21 \\
AD & NINCDS-ADRDA with exclusion of MID & 61 & 49 \\
Unclassifiable & 8 & 6 \\
\hline
\end{tabular}

ADDTC criteria (1992)

$\begin{array}{llrr}\mathrm{VaD} & \text { probable IVD } & 156 & 12\end{array}$

Mixed possible IVD $\quad 9 \quad 7$

AD NINCDS-ADRDA with exclusion of IVD $\quad 66 \quad 54$

$\begin{array}{lll}\text { Unclassifiable } & 19 \quad 15\end{array}$

\begin{tabular}{|c|c|c|c|}
\hline \multicolumn{4}{|c|}{ NINDS/AIREN(1993) } \\
\hline $\mathrm{VaD}$ & probable & 8 & \\
\hline Mixed & possible & 32 & 26 \\
\hline$A D$ & $\begin{array}{l}\text { NINCDS-ADRDA with exclusion of VaD by } \\
\text { NINDS criteria }\end{array}$ & 63 & 50 \\
\hline Unclas & & 6 & \\
\hline
\end{tabular}

MID $=$ Multi-infarct dementian, $P V D=$ probable $\mathrm{VaD}$ [12]; IVD $=$ ischemic VaD [14]; NINCDS-ADRDA: criteria for AD by NINCDSADRDA work group [16]; unclassifiable = not classifibable as either $\mathrm{VaD}$, $A D$ or mixed dementia. 
Table 3. Agreement ( $\mathrm{k}$ values) between the different sets of criteria for the diagnosis of $\mathrm{VaD}$ and $\mathrm{AD}$

\begin{tabular}{lllllll}
\hline & H-IS & R-IS & LIS & DSM-II ERK & ADDTC \\
& & & & & & \\
R-IS & 0.87 & - & - & - & - & - \\
L-IS & 0.74 & 0.70 & - & - & - & - \\
DSM-III & 0.50 & 0.49 & 0.56 & - & - & - \\
ERK & 0.37 & 0.36 & 0.58 & 0.40 & - & - \\
ADDTC & 0.40 & 0.39 & 0.62 & 0.46 & 0.88 & - \\
NINDS & 0.32 & 0.28 & 0.46 & 0.38 & 0.60 & 0.57 \\
\hline Criteria for AD & & & & & & \\
R-IS & 0.91 & - & - & - & - & - \\
L-IS & 0.83 & 0.81 & - & - & - & - \\
DSM-III & 0.66 & 0.68 & 0.68 & - & - & - \\
ERK & 0.78 & 0.79 & 0.83 & 0.56 & - & - \\
ADDTC & 0.65 & 0.64 & 0.82 & 0.85 & 0.66 & - \\
NINDS & 0.81 & 0.83 & 0.79 & 0.52 & 0.96 & 0.62 \\
\hline
\end{tabular}

$E R K=$ Criteria of Erinjuntti et al. $k$ statistics, interpretation of the level of agreement: $0.0-0.2$, slight; $0.2-0.4$, fair; $0.4-0.6$, moderate; 0.6 0.8 , substantial, and $0.8-1.0$, almost perfect [19].
The R-IS and H-IS resulted in the highest number of patients with $\mathrm{VaD}(36$ and 32 , i.e. 29 and $26 \%$, respectively), whereas only 8 $(6 \%)$ of the subjects were diagnosed as having $\mathrm{VaD}$ when the NINDS criteria were used. The number of patients diagnosed as having $\mathrm{AD}$ varied between $59(48 \%)$ using the DSM criteria and $70(56 \%)$ using the L-IS. Between 0 and $26 \%$ of the patients were diagnosed as suffering from mixed dementia, using the DSM criteria and those of the NINDS, respectively. The proportion of patients who could not be classified ranged from $32 \%$ (using the DSM criteria) to $2 \%$ (using the $\mathrm{H}-\mathrm{IS}$ ).

In table 3 , the $k$ values for $V a D$ and $A D$ between all possible combinations for criteria are shown. On the average, the agreement was substantial for $\mathrm{AD}(\mathrm{K}=0.75)$ but only moderate for $\operatorname{VaD}(k=0.52)$, whereas only fair agreement existed for mixed dementia ( $K=$ 0.32 ). Concerning the diagnosis of $\mathrm{VaD}$, substantial or even almost perfect agreement existed between the criteria of the ADDTC,
Erkinjuntti et al. 13] and the NINDS, as well as between the ISs. In general, there was only fair to slight agreement between the ISs and the modern criteria (ADDTC, Erkinjuntti and NINDS).

The lowest agreement for the diagnosis of VaD occurred between the H-IS and the R-IS on the one hand, and the criteria fo the ADDTC, Erkinjuntti et al. and the NINDS on the other. For instance, 32 patients had an $\mathrm{H}$ IS score indicative of $\mathrm{VaD}$, but no more than 8 would have been diagnosed as such according to the NINDS criteria. Common reasons for this disagreement were the following: 4 of the 32 patients diagnosed as having $\mathrm{VaD}$ by the H-IS criteria demonstrated slight unexplained focal signs and/or symptoms (e.g. onesided palmomental reflex), whereas the fifth patient demonstrated a fluctuating course and scored on the one-point behavioral items of the H-IS, leading to a high H-IS score, however, they also had an insidious onset of dementia with neither a clinical history of 
stroke nor hypodense areas on the $\mathrm{CT}$ scan and were thus diagnosed as having $\mathrm{AD}$ using the NINDS criteria for the exclusion of $\mathrm{VaD}$; 9 other patients with $\mathrm{VaD}$ according to the $\mathrm{H}$ IS were classified as having possible dementia by the NINDS criteria - 3 patients with Binswanger's disease without multiple strokes and 6 with evidence of only 1 stroke without a clear temporal connection with dementia. Six patients identified with the $\mathrm{H}$-IS as having $\mathrm{VaD}$ could not be classified by the ADDTC or the NINDS criteria: 3 patients were said to have become demented acutely instead of insidiously (thus not fulfilling criteria for AD); there was also no evidence of stroke in the history, the physical examination or on the CT scan (thus not fulfilling the criteria for possible or probable $\mathrm{VaD}$ ). Three other patients became demented after having a single stroke clinically, without any demonstrable hypodense areas on the CT scan. The ADDTC and the NINDS criteria do not cover these two situations, but Erkinjuntti's criteria would have classified them as mixed dementia.

\section{Discussion}

The present study shows that application of the seven sets of criteria for the diagnosis of $\mathrm{VaD}$ (or for the exclusion of vascular factors for $A D$ ) led to differences in the frequency of $\mathrm{AD}$ and $\mathrm{VaD}$ that cannot be neglected. For example, applying the R-IS resulted in more than twice as many patients with $\mathrm{VaD}$ as when the DSM-III-R criteria were applied. The more recent criteria showed substantial agreement with each other as did the ischemic scales. Otherwise, the sets of criteria cannot be interchanged without due consideration. In the 'clear-cut' patients, i.e. in those who demonstrated clear evidence of multiple strokes in their histories, clinical examinations and $\mathrm{CT}$ scans, different criteria led to similar diagnoses. The criteria diverged when information from one category did not confirm the other, e.g. evidence of stroke in a CT scan without focal neurological symptoms or vice versa. The present study shows that if the temporal connection or neuroimaging data are taken into account, the diagnostic outcome is influenced considerably. The choice of a particular set of criteria appears more critical in demonstrating a vascular etiology for the diagnosis of $\mathrm{VaD}$ than in making such an etiology unlikely for the diagnosis of $\mathrm{AD}$.

The controversy as to whether $\mathrm{VaD}$ is overdiagnosed [20] or underdiagnosed [21] may be related to differences in the criteria used, which is possibly an overlooked source of interstudy outcome variance; e.g. in a recent epidemiological study in Sweden, differences in diagnostic criteria were found to lead to a great variation in the prevalence of $\mathrm{VaD}$ [3]. Likewise, ischemic infarcts have been described as varying from 20 to $90 \%$ of the patients with $\mathrm{VaD}$ and from 0 to $37 \%$ of the patients with AD [7, 22-24]. Depending on which criterion was used, ischemic infarcts on CT scans were found in our study in $45-100 \%$ of the patients diagnosed as having $\mathrm{VaD}$, and in 0-13\% of the patients with AD.

In the absence of neuropathological data, no definite conclusion can be drawn as to which criterion is superior. For the diagnosis of $\mathrm{VaD}$, the more strict criteria of Erkinjuntti, the ADDTC and the NINDS seem preferable because they lead to more homogeneous patient groups. All versions of the IS can be regarded as clinically useful tools for the exclusion of a vascular etiology in the diagnosis of AD. 


\section{Conclusion}

Results of studies which use different criteria for the diagnosis or the exclusion of $\mathrm{VaD}$ must be compared with caution. Given the impact of temporal connection and neurora- diological data, the more recent criteria of the ADDTC, the NINDS and Erkinjuntti can presently be regarded as the choice criteria, although they still await further validation by pathological studies.

\section{References}

1 Hachinski W: Prewentable dementia: A call for action agaimst the wascular dementias. Lancet 1992;340645648.

2. Larson EB: Ilnesses causing dementha in the very elderly. N Engl J Med $1993 ; 328: 203-205$

3. Skoog 1, Nillsson L, Palmertz B, Andreasson L, Svanborg A: A popula tion-based study of denentia in 85 year-olds. N Engl I Med 1993;328: $153-158$

4 American Psychiaric Association; Diagnostic and Statistical Manual of Mental Disorders, ed 3 new. Washington, American Psyctriatric Association, 1987.

5 American Psychiatric Assogiation: Diagnostic and Statistical Manual of Mental disorders, ed 4. Washington, American Psychiatric Association, 1994.

6 Werhey FRI, dolles $J_{*}$ Ponds RWHM, Rozendelal N, Pugge $\mathrm{L}, \mathrm{de}$ Vet HCW, Vreeling FW, van der Lugt PJM: Dianosing dementia: $A$ companson between a monodisciplintry and multidisciplinary approach. I Neuropsychatry Chin Neurosci $1093.5: 78-85$.

7 Erkinjund T, Kotonen L, Sulkawa R, Vuoriatho M, Pallo J: CT in the differentall dugnosis between Alzhomer's dicerase and wasculat dementia. Acta Neurol Scand 1987;75: $262-270$

8 Hachinski V, Mllif LK, Zilkha E, Du Boulty G. McAllister $\mathrm{V}_{\text {" Marshall }} \mathrm{I}$, Ross Russell RW, Symon L: Cerebral blood now in dementia. Arch Neurol 1975:32:632-637.

9 Rosen WG, Tery R, Fuld PA. Katsman R. Peck A: Pathological verificat ton of ischentic score in the differentiation of dementias. Ann Neurol 1980;7:486an-488.
10 Loeb C: Clinical diagnosis of multinfarct dementia; in Amaduce L (ed): Aging of the Brain and Dementia. Aging. New York, Raven Press, 1980, wol 13, pp 251 - 260 .

11 Loeb $C$, Gandolfo $C$. Diagnostic ewaluation of degenerative and vascular dementia. Stroke 1983;14: $399-401$.

12 Erkinjuntti T: Differential diagnosis between Alheimer's disease and vascular dementia: Evaluation of common clinical methods. Acta Neurol Scand 1987;76:433-442.

13 Enkinjunti T, Haltia M, Palo J, Sul. kava R, Paetau A: Accuracy of the clinical diagnosis of vascular dementia: A prospective clinical and post-mortem neuropathological study. J Neurol Neurosurg Psychiatry 1988:51:1037-1044.

14 Chui HC, Victoroff $\mathrm{J}$, Margolin DM, Jagusi W, Shankle R, Katzman $R$ : Criteria for the diagnosis of ischemio wasculat dementia proposed by the State of California Alzheimer"s Diseasc Diagnosic and Treatment Centers. Neurology 1992;42:473480 .

15 Roman GC, Tatemichi TK, Erkinjuntti $\mathrm{T}$, Cummings $\mathrm{JL}_{\text {, }}$, Masdeu $\mathrm{JC}$, Garcia JH, Amaduce L, Orgogozo I-M, Brun A, Holman A Vascular dementia: Diagnostic criteria for research studies. Report of the NINDS.AIREN international workshop. Neurology 1993:43:250-260.

16 Mckhann $C$, Drachmann D, Folstein M, Katzmnn $R$, Price D, Stadlan E: Clinical diagnosis of Azheimer's disease: Report of the NINCDSADRDA workgroup under the auspices of the Department of Heallh and Human Services task force on Alzhemer's disease. Nenrology $1984 \times 34: 939-944$.
17 Folstem $M$, Folstein S, McHugh $P$ : 'Mini-Mental State': A practical method for grading the cognitive state of patients for the clinician. J Psychiatr Res 1977;12:189-198.

18 Hachinski VC, Potter P, Merskey H: Multi-infaret dementia: A cause of mental deterionation in the elderly. Lancet 1974,ii:207-210.

19 Landis JR, Koch GG: The measurement of observer agreement for categorical data. Biometrics 1977;33: $159-174$

20 Brust JCM: Vascular dementia is overdiagnosed. Arch Neurol 1988; 45:799-801.

21 O'Brien MD: Vascular dementia is underdiagnosed. Arch Neurol 1988; 45:797-798.

22 Radue EW, Boulay GHD, Harrison MJG, Thomas DJ: Comparison of angographic and $\mathrm{CT}$ scan findings between patients with multiinfarct dementia and those with dementia due to primary neuronal degeneralion. Neuroradiology $1978: 16: 113-$ 115.

23 Robers MA, MoGeonge AP, Caird FI: Electroencephalography and computerised tomography in vascular and non-vascular dementia. $J$ Neurol Neurosurg Psychiatry 1978; 41:903-906

24 Soininen H, Puranen M, Riakkinen PJ: Computed tomography findings in senile dementia and normal aging. I Neurol Neurosurg Psychiatry $1982 ; 45: 50-54$. 